\title{
Chromosomal DNA fingerprinting-a new method of species and strain identification applicable to microbial pathogens
}

\author{
R. J. OWEN
}

National Collection of Type Cultures, Central Public Health Laboratory, Colindale Avenue, London NW9 5 HT

\section{Introduction}

DNA-probe technology has enormous potential in clinical diagnostic microbiology. It offers the possibility of faster and cheaper identification of fastidious pathogens, including the detection of strains bearing known virulence factors and genes conferring resistance to antibiotics, and allows the direct detection of infectious agents in clinical specimens and in contaminated foods. There is a wealth of information, about these and other applications in microbiology that has been reviewed at length (Highfield and Dougan, 1985; Edberg, 1986; Goldmann, 1987; Miotti, 1987; Tenover, 1988; Landegren et al., 1988).

In the field of microbial identification, diagnostic probes are commercially available to detect various bacterial species including Legionella pneumophila, Mycobacterium tuberculosis, Neisseria gonorrhoeae, enteropathogenic Escherichia coli, Mycoplasma pneumoniae and some Salmonella serotypes (Tenover, 1988). Another application, of increasing interest to epidemiologists investigating and controlling hospital and community outbreaks, is the use of probes in providing DNA fingerprints for identification. Because these DNA fingerprints are highly sensitive to minor genomic variations in nucleotide sequences, they offer a precise means of characterising species and of identifying individual strains of closely related bacteria when more traditional typing methods are unsuitable or unavailable.

The purpose of this review is to describe the uses of chromosomal-DNA fingerprints in clinical and public-health microbiology. The methodologies involved, their application to species and strain identification, and their potential for typing bacteria will be discussed.

\section{Chromosomal digest analysis}

For the past 25 years, analyses of genomic DNA

Received 24 Feb. 1989; accepted 15 Mar. 1989. by base-composition ( $\mathrm{G}+\mathrm{C} \mathrm{mol} \%$ ) estimation and DNA-DNA hybridisation have provided an invaluable basis for defining closely related groups of microbial strains. DNA-DNA relatedness of c. $\geq 70 \%$ and a low level of sequence divergence are now generally regarded as the phylogenetic basis for defining species (Wayne et al., 1987). However, DNA-DNA homology measurements between total genomes are not sensitive enough to detect the small variations within species revealed by epidemiological typing methods such as serotyping, bacteriophage typing, resistotyping and biotyping. The alternative, novel, molecular methods that are now becoming more widely used (Goldmann, 1987; Falkiner, 1988) including plasmid and wholecell protein electrophoretic profiling and chromosomal restriction-enzyme analysis (REA), the latter also referred to as bacterial restriction-endonuclease digest-analysis (BRENDA).

BRENDA provides a sensitive means of directly detecting minor genomic differences between micro-organisms. Restriction endonucleases specifically cleave DNA into different lengths, depending on the number and position of the individual recognition sequences, provided that they have not been modified in any way. A DNA polymorphism refers to the change in the size of a restriction fragment. If a change occurs in the sequence of the genome DNA - even a single nucleotide-base mutation-this can delete a site or create a new recognition site and result in the generation of a restriction fragment-length polymorphism (RFLP). Sequence changes may also arise as a result of insertions, deletions or inversions of DNA between sites. RFLPs are most specific and reliable when the relevant gene has been located, its sequence has been defined and a probe has been made that is complementary to the sequence. Even if a change does not specifically involve restriction-site sequences, it may still be detected if the relevant fragments contain a suitable target sequence. The significance of DNA polymorphisms is that they 
most often represent neutral mutations and do not cause any phenotype change.

The restriction enzyme-recognition sites consist, in most cases, of four or six nucleotides arranged in a specific order with diad symmetry. Because the genomes of bacterial species vary widely in their base compositions $\left(26-72 \mathrm{~mol}^{\circ} \mathrm{G}+\mathrm{C}\right)$, the distribution of fragment sizes produced by restrictionenzyme digestion can also be expected to vary considerably. The expected frequency $a$ of restriction sites can be predicted from

$$
a=\left(\frac{\mathrm{g}}{2}\right)^{\mathrm{r}^{1}}\left(1-\frac{\mathrm{g}}{2}\right)^{\mathrm{r}^{2}}
$$

where $g$ is the fractional $G+C$ content of the genome DNA, $r^{1}$ is the number of $\mathrm{G}+\mathrm{C}$ base pairs and $r^{2}$ the number of $A+T$ base pairs in the recognition site (Nei and $\mathrm{Li}, 1979$ ). The expected number of restriction sites is then given by frequency $\times$ genome size. The genome sizes of most prokaryotic DNAs fall in a tenfold range between 800 and $8000 \mathrm{~kb}$ with a typical genome being about $6 \times 10^{6}$ bases in length (Gillis and DeLey, 1975). Because of the large sizes involved, it is impossible to predict accurately to what extent a restriction enzyme will cut a particular DNA. However, calculations on the basis of base composition as a predictor provide some information about likely cutting frequencies. Thus, the probability of a $\mathrm{G}+\mathrm{C}$-rich site in a $\mathrm{G}+\mathrm{C}$-rich DNA is about 1 in 500 but only 1 in 80000 in a $\mathrm{G}+\mathrm{C}$-poor DNA. The frequency of occurrence of particular sets of nucleotides is also a useful indicator. McClelland $e t$ al. (1987) showed that restriction endonucleases such as $X b a \mathrm{I}, A v r I I, S p e I$ and NheI with CTAG in their recognition sequences cleave less than once every 10000 bases. In contrast, CCG and CGG are the rarest trinucleotides in many genomes with base compositions of $<45 \mathrm{~mol} \% \mathrm{G}+\mathrm{C}$, and so enzymes such as SmaI, RsrII, NaeI and SacII, which have those sets of bases in their recognition sequences, are rare cutters for low $\mathrm{G}+\mathrm{C}$-content DNAs.

The DNA fragments generated by restrictionenzyme digestion are separated according to size by electrophoresis in agarose gels to give a pattern of bands (fig. 1). Conventional electrophoretic techniques resolve fragments ranging in size from about 100 bases to 20000 bases but recent developments by pulse-field electrophoresis enable much larger fragments $(>9000 \mathrm{~kb})$ to be separated (McClelland et al., 1987; Sor, 1988). Restriction endonuclease-digest patterns have been used to distinguish between strains of various bacteria
Table I. Bacterial species of medical importance examined by restriction-endonuclease digest analysis to discriminate among strains

$\begin{array}{ll}\text { Branhamella catarrhalis } & \text { Listeria monocytogenes } \\ \text { Brucella melitensis } & \text { Mycobacterium bovis } \\ \text { Campylobacter jejuni } & \text { M.tuberculosis } \\ \text { C.pylori } & \text { Mycoplasma pneumoniae } \\ \text { C.fetus } & \text { Neisseria meningitidis } \\ \text { Clostridium difficile } & \text { N.gonorrhoeae } \\ \text { Corynebacterium diphtheriae } & \text { Providencia stuartii } \\ \text { Cor. jeikeium } & \text { Pseudomonas aeruginosa* } \\ \text { Legionella pneumophila } & \text { Vibrio cholerae } \\ \text { Leptospira interrogans } & \end{array}$

* This species was examined by pulse-field electrophoresis
(Grothues and Tummler, 1987) whereas all other species were
tested by conventional electrophoresis techniques (for further details, see Owen, 1984).

(table I) including a number of genera with species of medical importance (e.g., Campylobacter, Legionella and Mycobacterium) as well as strains of other microbial groups such as Candida, Chlamydia, Giardia and cytomegalovirus. The usefulness of such patterns as diagnostic tools is limited by their complexity because they may comprise $\geq 50$ bands of various sizes, depending on the cutting frequency of the restriction endonuclease used and the genome size of the organism. It is difficult, therefore, to identify minor, but possibly significant, RFLPs in complex multiband patterns of closely related strains. There is also the possibility, when strains contain plasmids, that significant differences in the chromosomal-band pattern are obscured by the background pattern resulting from complete or partial digestion of the plasmid DNA. The detection of strain differences in DNA fingerprints relies largely on direct visual comparisons but computer methods have been used to make more objective comparisons between strain fingerprints (Sorensen et al., 1985; Ades et al., 1988; Bruce et al., 1988).

\section{Chromosomal probe-hybridisation patterns}

When the separated DNA fragments are transferred by capillary blotting on to nitrocellulose or nylon membranes (Southern, 1975), the location on the membrane of a restriction fragment containing a particular gene or nucleotide sequence can be determined by hybridisation with a specific labelled nucleic-acid probe. The resultant hybrid-band pattern provides a unique and reproducible fingerprint, described as the chromosomal probe pattern (Tompkins et al., 1986). The DNA-hybridisation reaction consists of the probe, the target DNA and a reporter molecule on the probe. The key compo- 


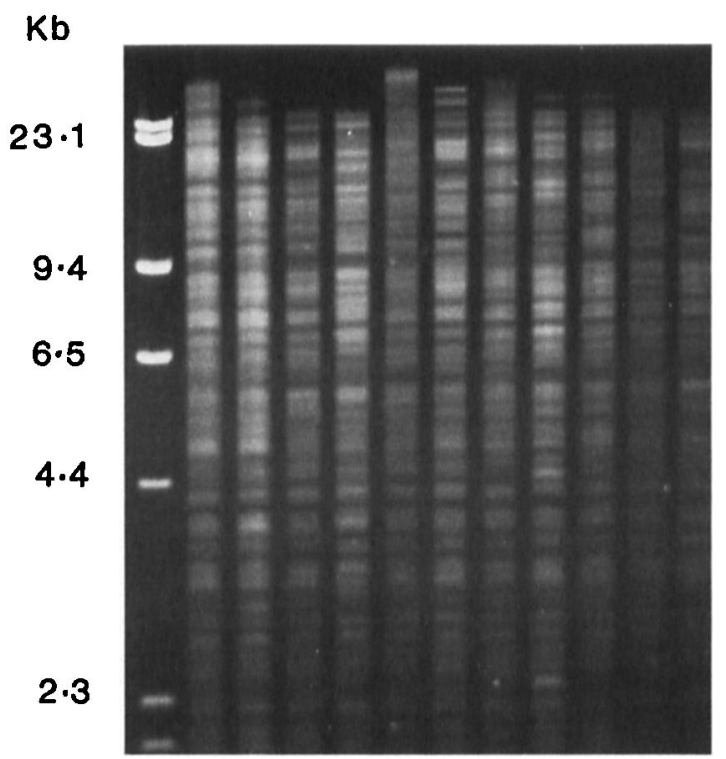

Fig. 1. Agarose-gel electrophoresis of ethidium bromide-stained EcoRI digest fragments of chromosomal DNA from strains of Prov. rettgeri (total-DNA restriction-digest patterns).

nent in Southern-blot hybridisation is the probe, which is a sequence of single-stranded nucleotides containing a reporter molecule that can search out and hybridise to stretches of the target DNA- or RNA-containing complementary sequences. The possibilities for probe design are almost infinite but, broadly, they fall into two categories. Firstly, there are short probes, which are usually chemicallysynthesised oligomers of $c$. 20 nucleotides, long enough to represent statistically unique sequences in the genome but sufficiently short to be destabilised by an internal mismatch in a target-probe sequence hybrid. Secondly, there are probes comprising longer nucleotide sequences, which may be between 100 or several thousand bases long, and may comprise sequences representing a significant part of the genome including specific gene sequences.

Nucleic-acid probes are used in Southern-blot hybridisation analyses with the purpose of highlighting specific DNA restriction-site heterogeneities, which in turn can be used to detect strain differences both within and between species (fig. 2). The advantage of this technique is that it greatly reduces the number of bands in the fingerprint and so facilitates comparisons between strains. Its disadvantage is that it provides information about specific regions only within the genome. The various probes used for this purpose include cloned random chromosomal sequences (Tompkins et al., 1986), toxin-production genes (Pappenheimer and Murphy, 1983) and, most widely used of all, ribosomal (r)RNA sequences. The rRNA-based probes provide a widely applicable system to investigate the molecular epidemiology of diverse bacteria (Grimont and Grimont, 1986; Stull et al., 1988) whereas other probes may be more limited in being speciesspecific or specific only for strains within a particular species.

The rationale for using rRNA genes in DNA fingerprinting has its basis in evolutionary history because such sequences are known to be highly conserved (Woese, 1987). A bacterial rRNA cistron has a total sequence of about 4600 bases comprising several subsequences, which include genes for $23 \mathrm{~S}$ rRNA ( $\sim 2500$ bases), 16S rRNA ( 1500 bases), $5 \mathrm{~S}$ rRNA ( $\sim 120$ bases) and various intervening and flanking sequences. In eubacteria, the rRNA genes are a small $(c .0 \cdot 1 \%)$ but highly conserved part of the genome and are found in clusters (rRNA operons) within which they are usually linked in the order 16S-23S-5S. Furthermore, the rRNA cistrons are present in multiple copies, which vary from species to species but mostly number 11 or less. In bacteria many of the rRNA-cistron sequences appear to have changed little during evolution and so DNA probes specific for these sequences can detect a wide range of bacteria containing similar sequences. Evidence for their conservation is provided by computed homologies between known sequences of rRNA molecules from different species. The partial 16S rRNA sequences of species in the genus Campylobacter, for example, are well documented (Thompson et al., 1988) and phylogenies based on such data have been constructed. Homologies between 16S rRNA sequences of different Campylobacter species are in the range $85-95 \%$, and there is a significant degree of homology of about $80 \%$ between them and Escherichia coli, and representatives of other gramnegative prokaryotes even though they are phylogenetically distant from Campylobacter (Thompson et al., 1988). The fact that E. coli and Pseudomonas aeruginosa rRNA hybridise in vitro with rRNA cistrons of a wide range of gram-negative and grampositive bacteria further supports the view that such sequences are highly conserved (Grimont and Grimont, 1986).

\section{Applications of chromosomal DNA-probe fingerprinting}

A number of microbial groups has been studied by means of chromosomal DNA-probe fingerprints 


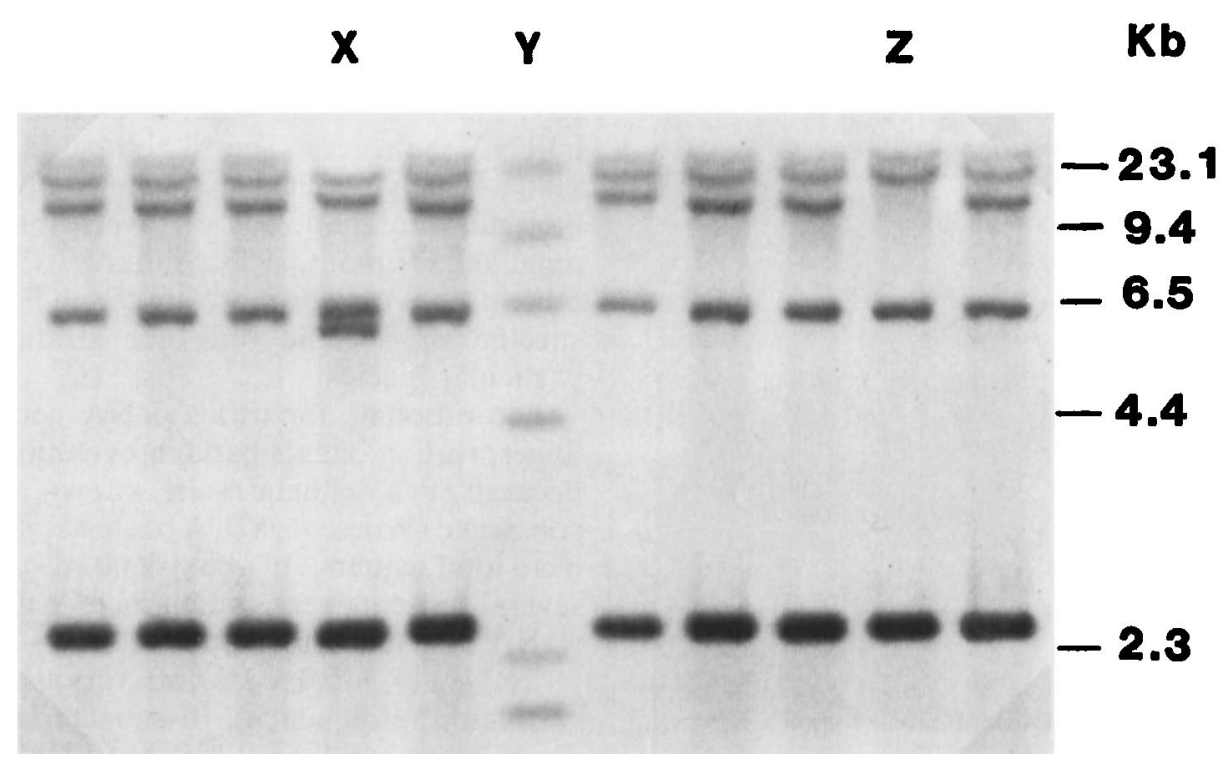

Fig. 2. Southern blot-hybridisation patterns of $P$. aeruginosa strains. A biotin-labelled ribosomal cDNA probe was hybridised by standard procedures (Owen et al., 1988) to filter-bound chromosomal-DNA HindIII fragments. All strains had identical fingerprints except for those marked $\mathrm{X}$ and $\mathrm{Z}$, which had single-band differences. Lane $\mathrm{Y}$ is an HindIII digest of bacteriophage $\lambda$ DNA to provide molecular size markers. (Results kindly provided by Dr D. Pitcher).

with the purpose of distinguishing either between allied species or between strains within a species. In a broad-ranging study, Grimont and Grimont (1986) used a ${ }^{32} \mathrm{P}$-labelled $E$. coli $16+23 \mathrm{~S}$ rRNA probe to detect rRNA genes in c. 40 different species of gram-positive and gram-negative bacteria, and among the species of medical interest examined there were representatives of Salmonella, Brucella, Serratia, Pseudomonas, Mycobacterium and Listeria. They found that the probe reacted with portions of rRNA genes in the DNA of species that were phylogenetically remote from $E$. coli, and that each species could be characterised by one or several specific patterns of rDNA-restriction fragments. Available DNA-hybridisation data showed that identical patterns were highly correlated with insignificant divergence. Furthermore, different patterns within species corresponded to significant divergence as evaluated by thermal-stability studies of DNA-DNA hybrids. The species examined and the probes and restriction enzymes used are summarised in table II. The results obtained on the species of medical interest are considered in more detail below.

\section{DNA fingerprints of mycoplasmas and allied genera}

This technique has been extensively applied to the mycoplasmas (class Mollicutes) and has pro- vided a novel approach to the differentiation and identification of different species and strains. Several studies have described the use of plasmid pMC5 as a probe. This recombinant plasmid carries the 5S and 23S RNA genes and part of the 16S gene of one of the two rRNA operons of Mycoplasma capricolum (Amikam et al., 1982; Glaser et al., 1984). Due to the highly conserved nature of the prokaryotic rRNA genes, this plasmid hybridises with DNA-containing rRNA genes of any mycoplasma and so can be used in their detection and identification (Razin, 1985). When mycoplasmal DNA is cleaved with a restriction enzyme such as EcoRI, the hybridisation pattern consists of a relatively small number of bands because of the presence of only one or two copies of the rRNA genes in the mycoplasmal genome and the relatively few restriction sites within the operons. Because the rRNA operons in the various mycoplasmas may differ in restriction sites within the operons and in their flanking sequences, resulting hybridisation patterns are unique for the different species. Such RNA-probe hybridisation patterns revealed genotypic heterogeneity among Acholeplasma laidlawii and Myco. hominis strains but a remarkable degree of homogeneity among Myco. pneumoniae strains isolated from pneumonic patients during a 10-year period (Yogev et al., 1988a). The genomic fingerprints of the $A$. laidlawii strains highlighted 
differences that were not observed with the serological or biochemical tests used to differentiate these strains. The homogeneity of the Myco. pneumoniae strains was reflected also in their antigenic composition based on immunoblots and convalescent patient sera. Strain variation within Myco. hominis rRNA genes was also analysed with a cloned fragment of the rRNA-gene from $\mathrm{Myco}$ plasma strain PG50 inserted in pMYC147 (Christiansen et al., 1987a) and with a probe containing fragments of the genes for the $\alpha$ and $\gamma$ subunits of the ATP synthase (atp) genes (Christiansen et al., $1987 b$ ). Both probes revealed considerable heterogeneity within $M y c o$. hominis although the subdivisions obtained by the different probes did not correspond. Another conserved-gene probe, namely the $E$. coli tuf gene coding for elongation-factor protein $(\mathrm{EF}-\mathrm{Tu})$, produced hybridisation patterns that confirmed the genotypic homogeneity of $M y c o$. pneumoniae strains and the distinctions observed previously by Yogev and Razin (1986) among Myco. gallisepticum strains (Yogev et al., 1988b). Other examples where these probes have proved useful include use in distinguishing the live vaccine F strain of Myco. gallisepticum from virulent field isolates of the avian pathogen and in detecting the $F$ strain in areas where vaccination with the $F$ strain took place (Yogev et al., 1988a). The pMC5 rRNA gene probe was also tested as a means of detecting mycoplasmas in infected plants and insect material (Nur et al., 1986). However, the probe reacted strongly with the rRNA-gene sequences of the plant chloroplasts and its use in detecting mycoplasmas in plants was hampered.

All the probes used in the above studies showed clear differences between the various species in their hybridisation-band patterns.

\section{DNA fingerprints of gram-negative eubacteria}

\section{Providencia}

A biotin-labelled cDNA synthesised by reverse transcriptase from a mixture of $16 \mathrm{~S}$ and $23 \mathrm{~S}$ rRNA from Providencia stuartii was used to identify rRNA cistrons in Southern blots of EcoRI and HindIII digests of Providencia total chromosomal DNA. The Prov. stuartii rDNA fingerprint was quite distinct from those of allied Providencia and Proteus species and 11 EcoRI-digest pattern-probe types were detected among the 26 strains of Prov. stuartil examined from hospitals in the UK (Owen et al., 1988). It was possible to detect strain differences with this probe that were not apparent in the total- digest patterns or in conventional test characters. This study demonstrated that biotin was an excellent probe-reporter molecule and a suitable alternative to the radiolabelled probes used in many other studies (table II). The pattern data were used also in a numerical analysis to provide a basis for estimating similarities between strains.

\section{Pseudomonas}

The genome of $P$. aeruginosa contains at least four sets of cistrons, each comprising the genes for 16S, 23S and 5S rRNA (Hartmann et al., 1986). The distance between the 16S- and 23S-rRNA coding sequences was estimated to be between 100 and 700 bases and recognition sites for EcoRI, HindIII and BamHI were identified within the rRNA sequences. In an epidemiological study of $P$. aeruginosa strains from patients with cystic fibrosis and a patient with endocarditis, strains were typed with a cloned 741 base-pair DNA probe derived from the region upstream of the exotoxin-A structural gene (Ogle et al., 1987). More than 100 $P$. aeruginosa strains were distinguished by probing Southern blots of DNA digested with various enzymes including $\mathrm{SalI}, \mathrm{Bg} I \mathrm{II}$ and $\mathrm{XhoI}$. Although only one hybrid fragment was detected in each strain blot, the target sequence proved to be a stable marker when tested under various in-vivo and invitro conditions. In many cases, typing of isolates with the probe confirmed the results obtained with serotyping, biotyping and antibiograms. The chromosomal-digest patterns supported the strain distinctions evident from the Southern-blot analysis, irrespective of the restriction enzyme used. The study also revealed that serial isolates (from individual patients), differing in morphology, serotype and antibiogram, were identical when compared in their probe-hybridisation patterns. Furthermore, isolates identical in serotyping, biotyping and antibiograms, but obtained from unrelated patients, were easily distinguished by their patterns.

Ribosomal-RNA genes were used as markers in a study of $P$. cepacia isolates from the sputum of patients with cystic fibrosis (Stull et al., 1988). A $P$. cepacia probe was hybridised with EcoRI digests of DNA from eight strains of $P$. cepacia and polymorphisms based on patterns that comprised between four and nine distinct bands were detected in the majority. The study also showed that the use of $E$. coli rRNA as a probe yielded similar RFLP patterns to the $P$. cepacia-derived rRNA probe and provided further evidence that $E$. coli rRNA offers a widely applicable system to investigate the 
Table II. Summary of microbial species investigated by chromosomal DNA-probe fingerprinting

\begin{tabular}{|c|c|c|}
\hline Species & Probe(s) & $\begin{array}{l}\text { Restriction endonu- } \\
\text { clease(s) used }\end{array}$ \\
\hline
\end{tabular}

Section 1. VARIOUS EUBACTERIA

Serratia, Salmonella, Citrobacter, Pseudomonas, Acinetobacter, Brucella, Listeria, mycobacteria, Bordetella and others

\section{Section 2. MYCOPLASMAS \\ Acholeplasma laidlawii}

Myco. gallisepticum

Myco. genitalium

Myco. hominis and other species

Myco.hominis

Myco. pneumoniae

Various Mycoplasma species
$16 \mathrm{~S}+23 \mathrm{~S}$ rRNA from $E$. coli and $P$. aeruginosa
EcoRI, BamHI, HindIII

Grimont and Grimont (1986)
pMC5 containing $16+$ 23S + part 16S rRNA gene of Myco capricolum

As above ptufA containing $E$. coli tufA gene and flanking sequences

rRNA gene probe $\mathrm{pMC5}$

pMYC4-containing insert of rRNA gene of $\mathrm{Myco}-$ plasma $\mathrm{PG} 50$

pMYC405 containing part of atp operon of $\mathrm{Myco}$ plasma PG50

pMC5 containing $5 S+23 S+$ part $16 S$ rRNA genes of $M y c o$. capricolum

As above

As above
EcoRI, PstI

HindIII

HindIII, Eco RI, BglII

HindIII

EcoRI

EcoRI, HindIII

EcoRI, $B g$ III

EcoRI, HindIII

Cla I

HindIII
Yogev and Razin (1986), Yogev et al. (1988a)

Yogev and Razin (1986)

Yogev et al. (1988b)

Yogev and Razin (1986)

Christiansen et al. (1987a)

Christiansen et al. (1987b)

Yogev et al. (1988b)

Yogev et al. (1988b) Yogev et al. (1988b)

\section{Section 3. GRAM-NEGATIVE EUBACTERIA}

Providencia stuartii,

Prov. alcalifaciens,

Prov. rustigianii,

Proteus vulgaris

Prot. vulgaris

Pseudomonas aeruginosa

P. cepacia

Haemophilus influenzae

$H$. influenzae biovar aegyptius

Salmonella typhimurium, $S$. enteritidis, $S$. dublin

Legionella pneumophila and other Legionella species

\section{Providencia and Proteus \\ Prov. stuartii $16 \mathrm{~S}+23 \mathrm{~S} \quad$ EcoRI, HindIII rDNA}

Synthetic oligonucleotide EcoRI probe PV25 of selected $16 \mathrm{~S}$ rRNA sequences

\section{Pseudomonas}

E. coli exotoxin-A gene and $\quad S a l$ I, XhoI, BglII, BamHI associated sequences E. coli $16 \mathrm{~S}$ and $23 \mathrm{~S} / 5 \mathrm{~S}$ rDNA

BamHI-EcoRI, BamHIHind III

E. coli and P. cepacia rRNA EcoRI

\section{Haemophilus}

E. coli and $H$. influenzae EcoRI

rRNA

E. coli rRNA EcoRI, EcoRV

\section{Salmonella}

Cosmid clones of S. enteriti- $\quad$ EcoRI, HindIII, PstI dis random genome sequences

\section{Legionella}

Cloned fragment containNciI ing $16 \mathrm{~S}+23 \mathrm{~S}$ rRNA genes of L. pneumophila
Owen et al. (1988)

Haun and Gobel (1987)
Ogle et al. (1987)

Hartmann et al. (1986)

Stull et al. (1988)

Stull et al. (1988)

Irino et al. (1988)

Tompkins et al. (1986)

Saunders et al. (1988) 


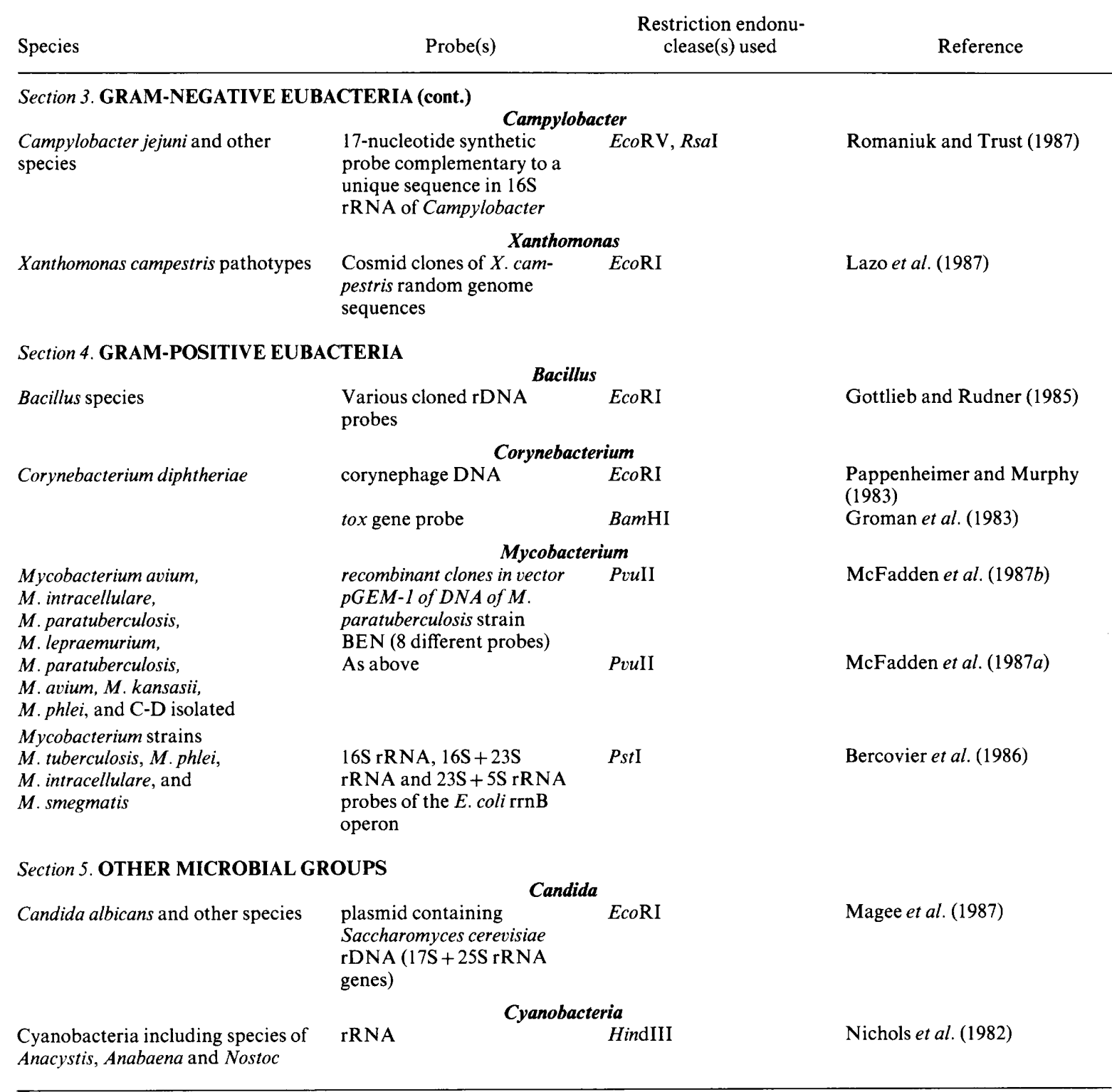

molecular epidemiology of genetically diverse bacteria.

\section{Haemophilus}

The binding patterns obtained from probing whole-cell DNA with $E$. coli rRNA were used to test the genetic relatedness of 10 non-typable isolates of $H$. influenzae (Stull et al., 1988). The banding patterns, comprising up to eight or nine bands, were heterogeneous except for those from three epidemiologically related strains from the trachea and blood of an infant and from the mother's cervix, all of which had identical patterns.

The rRNA gene-restriction patterns of 92 strains of $H$. influenzae biovar aegyptius that were associated with conjunctivitis or Brazilian purpuric fever (BPF) were studied by the use of $E$. coli $16+23 \mathrm{~S}$ rRNA as a probe (Irino et al., 1988). All strains were classified in one of 15 patterns, one of which was associated with most of the cases of BPF, although all patterns were seen among the conjunctival isolates. Most strains showed 6-8 strong bands and 1-5 weak bands. The efficiency of rRNA gene- 
restriction patterns as an epidemiological tool compared with clinical history, plasmid-restriction fingerprinting, protein electrophoresis and multilocus-enzyme electrophoresis was demonstrated in a companion study (Brenner et al., 1988) which showed that strains ascribed to two different RFLP patterns were not separated by any of the other methods.

\section{Salmonella}

Sequences of cloned chromosomal DNA were used as a probe to highlight restriction-site heterogeneity and to differentiate between strains of three Salmonella serotypes (Tompkins et al., 1986). Analysis of HindIII-digested DNA from isolates of S. typhimurium from 11 outbreaks by probing with cosmid-containing random chromosomal inserts from $S$. enteritidis, revealed six unique fingerprint patterns. Patterns containing about eight bands were reported for $S$. dublin and six different fingerprint patterns were observed in the 24 isolates of this serotype. The fingerprinting method detected differences in three strains that could not be demonstrated by other means. The probes clearly distinguished between the three Salmonella serotypes and all isolates considered to be epidemiologically and phenotypically distinct were grouped. Several isolates that were not related epidemiologically and had unique phenotypes (including plasmid profiles and phage types) nevertheless had similar chromosomal-probe fingerprint patterns. It was concluded that isolates giving homogeneous patterns were derived from a single clone, which had been disseminated to several geographical locations over a number of years. In some cases plasmids appeared to have been acquired by some clones after spread, so providing evidence of more recent evolution. These results suggested that $S$. enteritidis contained highly conserved sequences because isolates recovered over a 30 -year period from widely separated locations showed few variations.

\section{Legionella}

DNA probes have proved particularly useful in distinguishing $L$. pneumophila from allied species (Grimont et al., 1985), and in strain characterisation (Saunders et al., 1988). The latter workers used a cloned EcoRI DNA fragment from L. pneumophila, which included $16 \mathrm{~S}$ and $23 \mathrm{~S}$ rRNA genes, as a probe to identify members of the genus Legionella and they found that the type strains of 28 species gave different patterns in every case. Also the variation between and within strains of different recognised serogroups within L. pneumophila was assessed and variable patterns of at least 10 bands were detected in $N c$ iI DNA digests.

\section{Campylobacter}

EcoRV or RsaI digests of chromosomal DNA from strains of $C$. jejuni, C. fetus, C. coli and $C$. laridis were probed with a 17 nucleotide-long probe complementary to a unique sequence present in the $5^{\prime}$ domain of the 16S ribosomal RNA of Campylobacter (Romaniuk and Trust, 1987). Six distinct hybridisation patterns were obtained with differences between species as well as between individual members of the same species. It was suggested that DNA fingerprinting with this probe was a potentially useful identification method in epidemiological studies of Campylobacter infections.

\section{DNA fingerprints of mycobacteria}

The rRNA genes of a number of Mycobacterium species have been studied principally with the aim of distinguishing between species. Cox and Katoch (1986) found that the distribution of BamHI and EcoRI sites within the rRNA genes and flanking sequences of $M$. phlei and $M$. smegmatis were characteristic for each of these species. Hybridisation with labelled rRNA from those species revealed between three ( $E c o$ RI) and five bands (BamHI) containing homologous sequences. It was concluded that the sequences flanking the rRNA genes were not identical and that the sequences of the rRNA genes themselves were significantly different in the two species.

In studies of the rRNA genes of $M$. tuberculosis, $M$. intracellulare and other species (Bercovier et al., $1986)$ different regions of the $E$. coli rrnB operon were used as gene probes. It was concluded from the resulting hybridisation patterns that the slowgrowing species ( $M$. tuberculosis and $M$. intracellulare) appeared to possess only one rRNA operon whereas the faster-growing species $(M$. phlei and $M$. smegmatis) had two rRNA operons. Similar results were reported by Suzuki et al. (1987) who found that $M$. bovis strain BCG carried at most two copies of rRNA genes. The genes were arranged in the order 16S, 23S and 5S rRNA but no tRNA gene was detected in the spacer region between the $16 \mathrm{~S}$ and 23S rRNA genes. Cloned DNA from an unclassified Mycobacterium isolated for a patient with Crohn's disease (CD) was used as a probe to identify RFLPs in DNA samples from various 
species of Mycobacterium and to examine their relationships (McFádden et al., 1987a). It was found that three CD-isolated strains were indistinguishable from each other and from the type strain of $M$. paratuberculosis. Furthermore, many RFLPs were found that distinguished between $M$. paratuberculosis, representatives of the $M$. avium complex (serotypes 2 and 5), $M$. kansasii and $M$. phlei. The same DNA probes identified RFLPs providing evidence that the $M$. avium-complex could be divided into $M$. avium and $M$. intracellulare (McFadden et al., 1987b). These data were also used as the basis of a phylogenetic analysis of the $M$. aviumcomplex.

\section{DNA fingerprints of other microbial genera}

Other microbial groups not discussed above but examined by Southern-blot hybridisation analysis to distinguish both between different species and between strains within species include various cyanobacteria (Nichols et al., 1982), pathotypes of Xanthomonas campestris (Lazo et al., 1987), Bacillus species (Gottlieb and Rudner, 1985), Corynebacterium diphtheriae (Groman et al., 1983), and Candida albicans and associated species (Magee et al., 1987). Further details on the probes used are listed in table II.

\section{Comments and conclusions}

The substantial set of data now available on probe-hybridisation patterns of chromosomalDNA digests demonstrates that they provide a valuable new method of distinguishing among related species and, most significantly, of detecting variation among strains within species. The principal advantages and disadvantages of the method are summarized in table III. The most important advantage is the possibility that it offers a universally applicable method of identifying, and possibly of typing, any micro-organism. The approach is facilitated by the use of broad-spectrum probes, such as those based on rRNA genes, but other more specialised probes may be needed for increased discrimination or specificity within particular spe-

\section{REFERENCES}

Ades A E, Garrett A J, Cowell J, Chin K S, Peckham C S 1988 Computer matching of oligonucleotide patterns on electrophoretic gels: an application to the epidemiology of cytomegalovirus. Epidemiology and Infection 100: 467-479.

Amikam D, Razin S, Glaser G 1982 Ribosomal RNA genes in Mycoplasma. Nucleic Acid Research $10: 4215-4222$.

Bercovier H, Kafri O, Sala S 1986 Mycobacteria possess a
Table III. Advantages and disadvantages of DNA fingerprinting by probe hybridisation
Advantages
Applicable to any micro-organism
Reproducible
Wide range of restriction enzymes available
Commercially available rRNA can be used as a broad- spectrum probe
Biotin is an excellent reporter molecular in probes
Highly sensitive to minor genome variations
Patterns are relatively simple ( $\leq 10$ bands)
Pattern matching can be computerized*

\section{Disadvantages}
Methodologies relatively time consuming
Loci detected by probe may not be representative of genome

\begin{abstract}
* Commercially available software enables band detection, quantification and automatic pattern-matching (RFLP Interpretation Software, BioImage, Ann Arbor, MI, USA).
\end{abstract}

cies. Because the patterns are amenable to computer analysis, it should be possible in the future to establish data bases of profiles for identification purposes.

DNA fingerprinting is relatively laborious at present and, hence, unsuitable for routine use in the clinical laboratory. However, it has an important place in a reference laboratory if used in conjunction with existing methods of epidemiological typing, particularly in the investigation of strains that are untypable by other methods. Research is needed to evaluate fully DNA fingerprinting as a typing method, particularly in establishing its discriminatory power, although there is evidence that it is superior to some of the other methods currently used as shown for instance by the studies on $A$. laidlawii (Yogev et al., 1988a), C. albicans (Hunter and Gaston, 1988), H. influenzae (Brenner et al., 1988), P. aeruginosa (Ogle et al., 1987). Finally, it is important that the probehybridisation patterns should be interpreted in conjunction with the total chromosomal-digest patterns because in some circumstances the latter may provide a more sensitive measure of variation between closely related strains at the sub- and infrasubspecific level.

surprisingly small number of ribosomal RNA genes in relation to the size of their genome. Biochemical and Biophysical Research Communications 136: 1136-1 141.

Brenner D J et al. 1988 Biochemical, genetic and epidemiologic characterization of Haemophilus influenzae biogroup aegyptius (Haemophilus aegyptius) strains associated with Brazilian Purpuric Fever. Journal of Clinical Microbiology 26: 1524-1534.

Bruce D, Hookey J V, Waitkins S A 1988 Numerical 
classification of campylobacters by DNA-restriction endonuclease analysis. Zentralblatt für Bacteriologie Mikrobiologie und Hygiene Series A 269: 284-297.

Christiansen G, Andersen H, Birkelund S, Freundt E A $1987 a$ Genomic and gene variation in Mycoplasma hominis strains. Israel Journal of Medical Sciences 23: 595-602.

Christiansen C, Christiansen G, Rasmussen O F $1987 b$ Heterogeneity of Mycoplasma hominis as detected by a probe for atp genes. Israel Journal of Medical Sciences 23 : 591-594.

Cox R A, Katoch V M 1986 Evidence of genetic divergence in ribosomal RNA genes in mycobacteria. FEBS Letters 195 : 194-198.

Edberg S C 1986 Nucleic acid hybridization analysis to elucidate microbial pathogens. Laboratory Medicine 17: 735-738.

Falkiner F R 1988 Epidemiological typing : a user's view. Journal of Hospital Infection 11 : 303-309.

Gillis M, De Ley J 1975 Determination of the molecular complexity of double-stranded phage genome DNA from initial renaturation rates. The effect of DNA base composition. Journal of Molecular Biology 98: 447-464.

Glaser G, Amikam D, Razin S 1984 Physical mapping of the ribosomal RNA genes of Mycoplasma capricolum. Nucleic Acid Research 12: 2421-2426.

Goldmann D A 1987 New microbiological techniques for hospital epidemiology. European Journal of Clinical Microbiology 6 : 344-347.

Gottlieb P, Rudner R 1985 Restriction site polymorphism of ribosomal ribonucleic acid gene sets in members of the genus Bacillus. International Journal of Systematic Bacteriology 35: 244-252.

Grimont F, Grimont P A D 1986 Ribosomal ribonucleic acid gene restriction patterns as potential taxonomic tools. Annales de l'Institut Pasteur Microbiology 137B: 165-175.

Grimont P A D, Grimont F, Desplaces N, Tchen P 1985 DNA probe specific for Legionella pneumophila. Journal of Clinical Microbiology 21 : 431-437.

Groman N, Cianciotto N, Bjorn M, Rabin M 1983 Detection and expression of DNA homologous to the tox gene in nontoxinogenic isolates of Corynebacterium diphtheriae. Infection and Immunity 42: 48-56.

Grothues D, Tummler B 1987 Genome analysis of Pseudomonas aeruginosa by field inversion gel electrophoresis. FEMS Microbiology Letters 48: 419-422.

Hartmann R K, Toschka H Y, Ubrich N, Erdmann V A 1986 Genomic organization of rDNA in Pseudomonas aeruginosa. FEBS Letters 195: 187-193.

Haun G, Gobel U 1987 Oligonucleotide probes for genus-, species- and subspecies-specific identification of representatives of the genus Proteus. FEMS Microbiology Letters 43 : 187-193.

Highfield P E, Dougan G 1985 DNA probes for microbial diagnosis. Medical Laboratory Sciences 42: 352-360.

Hunter P R, Gaston M A 1988 Numerical index of the discriminatory ability of typing systems: an application of Simpson's index of diversity. Journal of Clinical Microbiology 26: $2465-2466$.

Irino K, Grimont F, Casin I, Grimont P A D The Brazilian Purpuric Fever Study Group 1988 rRNA gene restriction patterns of Haemophilus influenzae biogroup aegyptius strains associated with Brazilian purpuric fever. Journal of Clinical Microbiology 26: 1535-1538.

Landegren U, Kaiser R, Caskey C T, Hood L 1988 DNA diagnostics-molecular techniques and automation. Science 242: 229-237.

Lazo G R, Roffey R, Gabriel D W 1987 Pathovars of Xanthomonas campestris are distinguishable by restriction fragment-length polymorphism. International Journal of Systematic Bacteriology 37: 214-221.

Magee B B, D'Souza T M, Magee P T 1987 Strain and species identification by restriction fragment length polymorphisms in the ribosomal DNA repeat of Candida species. Journal of Bacteriology 169: 1639-1643.

McClelland M, Jones R, Patel Y, Nelson M 1987 Restriction endonucleases for pulsed field mapping of bacterial genomes. Nucleic Acids Research 15: 5985-6005.

McFadden J J, Butcher P D, Chiodini R, Hermon-Taylor J $1987 a$ Crohn's disease-isolated mycobacteria are identical to Mycobacterium paratuberculosis, as determined by DNA probes that distinguish between mycobacterial species. Journal of Clinical Microbiology 25: 796-801.

McFadden J J, Butcher P D, Thompson J, Chiodini R, HermonTaylor J $1987 b$ The use of DNA probes identifying restriction-fragment-length polymorphisms to examine the Mycobacterium avium complex. Molecular Microbiology 1: 283-291.

Miotti P G 1987 Rapid methods for the molecular diagnosis of infectious diseases: current trends and applications. European Journal of Epidemiology 3: 356-364.

Nei M, Li W-H 1979 Mathematical model for studying genetic variation in terms of restriction endonucleases. Proceedings of the National Academy of Sciences of the USA 76: 52695273.

Nichols J M, Foulds I J, Crouch D H, Carr N G 1982 The diversity of cyanobacterial genomes with respect to ribosomal RNA cistrons. Journal of General Microbiology 128 : 2739-2746.

Nur I, Bove J M, Saillard C, Rottem S, Whitcomb R M, Razin S 1986 DNA probes in detection of spiroplasmas and mycoplasma-like organisms in plants and insects. FEMS Microbiology Letters 35: 157-162.

Ogle J W, Janda J M, Woods D E, Vasil M L 1987 Characterization and use of a DNA probe as an epidemiological marker for Pseudomonas aeruginosa. Journal of Infectious Diseases 155: 119-126.

Owen R J 1984 Nucleic acid sequencing and fingerprinting in bacterial classification. In: Sanna A, Morace G (eds), New horizons in microbiology. Elsevier Science Publishers B.V, Amsterdam, pp 21-31.

Owen R J, Beck A, Dayal P A, Dawson C 1988 Detection of genomic variation in Providencia stuartii clinical isolates by analysis of DNA restriction fragment length polymorphisms containing rRNA cistrons. Journal of Clinical Microbiology 26: 2161-2166.

Pappenheimer A M, Murphy J R 1983 Studies on the molecular epidemiology of diphtheria. Lancet $2: 923-926$.

Razin S 1985 Molecular biology and genetics of mycoplasmas (Mollicutes). Microbiological Reviews 49: 419-455.

Romaniuk P J, Trust T J 1987 Identification of Campylobacter species by Southern hybridization of genomic DNA using an oligonucleotide probe for $16 \mathrm{~S}$ rRNA genes. FEMS Microbiology Letters 43: 331-335.

Saunders N A, Harrison T G, Kachwalla N, Taylor A G 1988 Identification of species of the genus Legionella using a cloned rRNA gene from Legionella pneumophila. Journal of General Microbiology 134 : 2363-2374.

Sor F 1988 A complete program allows the separation of a wide range of chromosome sizes by pulsed field gel electrophoresis. Nucleic Acids Research 16: 4853-4863.

Sorensen B, Falk E S, Wisloff-Nilsen E, Bjornvatn B, Kristiansen B E 1985 Multivariate analysis of Neisseria DNA restriction endonuclease patterns. Journal of General Microbiology 131 : 3099-3104.

Southern E M 1975 Detection of specific sequences among DNA 
fragments separated by gel electrophoresis. Journal of Molecular Biology 98: 503-517.

Stull T L, LiPuma J J, Edlind T D 1988 A broad spectrum probe for molecular epidemiology of bacteria : ribosomal RNA. Journal of Infectious Diseases 157: 280-286.

Suzuki Y, Yoshinaga K, Ono Y, Nagata A, Yamada T 1987 Organization of rRNA genes in Mycobacterium bovis BCG. Journal of Bacteriology 169 : 839-843.

Tenover F C 1988 Diagnostic deoxyribonucleic acid probes for infectious diseases. Clinical Microbiology Reviews 1: 82-101.

Thompson L M, Smibert R M, Johnson J L, Krieg N R 1988 Phylogenetic study of the genus Campylobacter. International Journal of Systematic Bacteriology 38: 190-200.

Tompkins L S, Troup N, Labigne-Roussel A, Cohen M L 1986 Cloned, random chromosomal sequences as probes to identify Salmonella species. Journal of Infectious Diseases 154: $156-162$.
Wayne L G et al. 1987 Report of the ad hoc committee on the reconciliation of approaches to bacterial systematics. International Journal of Systematic Bacteriology 37 : 463-464.

Woese C R 1987 Bacterial evolution. Microbiological Reviews 51 : $221-271$.

Yogev D, Razin S 1986 Common deoxyribonucleic acid sequences in Mycoplasma genitalium and Mycoplasma pneumoniae genomes. International Journal of Systematic Bacteriology 36 : 426-430.

Yogev D, Halachmi D, Kenny G E, Razin S $1988 a$ Distinction of species and strains of mycoplasmas (Mollicutes) by genomic DNA fingerprints with an rRNA gene probe. Journal of Clinical Microbiology 26: 1198-1201.

Yogev D, Sela S, Bercovier H, Razin S $1988 b$ Elongation factor $(\mathrm{EF}-\mathrm{Tu})$ gene probe detects polymorphism in Mycoplasma strains (FEM 03154). FEMS Microbiology Letters 50: 145149. 